\title{
Influence of a soft tissue layer covering the kidney upon blunt impact
}

Lea Siegenthaler ${ }^{1}$, Florian Sprenger ${ }^{1}$, Fabiano Riva ${ }^{1}$, Matthieu Glardon ${ }^{1}$, Beat P.

Kneubuehl ${ }^{1,2}$, Martin Frenz ${ }^{3}$

${ }^{1}$ Institute of Forensic Medicine, University of Bern, Bern, Switzerland

${ }^{2}$ bpk consultancy gmbh, Thun, Switzerland

${ }^{3}$ Institute of Applied Physics, University of Bern, Bern, Switzerland

E-mail: lea.siegenthaler@irm.unibe.ch

Tel.: +41316313326

Fax: +41316313833

URL: www.irm.unibe.ch

\begin{abstract}
Blunt abdominal organ injury is an abundant and relevant topic in forensic medicine yet comparatively few experimental studies have been performed to quantify organ injury threshold parameters. The goal of this study was to relate an impact to a kidney injury determining an energy threshold while taking account of the influence of the overlaying soft tissue thickness. A model consisting of ballistic gelatin with an embedded filled porcine kidney was made such that a gelatin layer of 2 or $4 \mathrm{~cm}$ thickness covered the organ. An impactor was dropped on this model from different heights and the resulting organ damage was categorized according to the abbreviated injury scale (AIS). The 50\% energy threshold for damage and the 50\% energy threshold causing injuries $\geq$ AIS 3 were determined for the two protecting soft layers to be $22 \mathrm{~J}$ and $32 \mathrm{~J}$ and $27 \mathrm{~J}$ and $36 \mathrm{~J}$, respectively. A finite element model was created to determine the strain energy densities at the depth of the organ's surface for these energies. The strain energy densities for the 50\% damage thresholds were $88.9 \mathrm{~mJ} / \mathrm{cm}^{3}$ and $86.7 \mathrm{~mJ} / \mathrm{cm}^{3}$ for 2 and $4 \mathrm{~cm}$ and for the injuries $\geq$ AIS 3 $104.2 \mathrm{~mJ} / \mathrm{cm}^{3}$ and $98.7 \mathrm{~mJ} / \mathrm{cm}^{3}$. For forensic cases this means that the thickness of the abdominal layers must be taken into account when the severity of an injury is used to draw conclusions about the applied impact strength.
\end{abstract}

\section{Keywords}

damage energy threshold, strain energy density, abdominal layers, blunt impact, kidney 


\section{Introduction}

Abdominal organs are very susceptible to trauma caused by blunt impacts because they are not protected by bony structures. In traffic accidents abdominal lesions are besides brain injuries [1-4] the cause of the second most fatal injuries. Apart from traffic accidents, more localized impacts can occur when less-lethal impact weapons (LLIW) are involved or when a victim is being hit or kicked in an assault. From the use of LLIW and the medico-legal point of view, the question of how much energy is needed to cause a serious injury to an organ becomes apparent.

In this study we focus on the kidney, an organ only partially protected by the ribs and therefore vulnerable but at the same time very important in filtering blood.

A number of studies had already been performed with the purpose of understanding the mechanical response of a kidney under impact load on human [5], porcine [6-15], and simian kidneys [16].

Melvin et al. [16] measured the maximum stress and strain and the strain energy density (SED) related to the organ injury. Although, their number of tests was very limited, they reported the appearance of first lacerations at a strain energy density of $27 \mathrm{~mJ} / \mathrm{cm}^{3}$. Bschleipfer et al. [11] found first lesions at an energy of $1.4 \mathrm{~J}$, a force of $160 \mathrm{~N}$, and at an acceleration of $132 \mathrm{~m} / \mathrm{s}^{2}$. They determined an energy threshold of $4 \mathrm{~J}$ for lesions measuring more than $60 \%$ of the craniocaudal length of the organ. Snedeker et al. [12] performed tests on samples of the renal cortex and on whole organs measuring the SED. Their samples ruptured within a range of 25$60 \mathrm{~mJ} / \mathrm{cm}^{3}$, whereas whole organs ruptured within a range of $15-30 \mathrm{~mJ} / \mathrm{cm}^{3}$ corresponding to an impact energy of 2.7-4.6 J. In a later study [13] they claimed the impact energy to be the best predictor of injury. They also confirmed the $4 \mathrm{~J}$ energy threshold for injuries with an abbreviated injury scale (AIS) grade 3 found by Bschleipfer et al. [11] at a corresponding SED of $25 \mathrm{~mJ} / \mathrm{cm}^{3}$. Further investigation by the same group [14] yielded to a $50 \%$ threshold of the SED of $21 \mathrm{~mJ} / \mathrm{cm}^{3}$ for an injury level AIS 3 and higher. Additionally, they developed a finite element method (FEM) model of the kidney, which allowed visualizing the SED distribution over the whole organ during the impact. At an impact of $4 \mathrm{~J}$ a large region of the parenchyma reached a SED higher than $60 \mathrm{~mJ} / \mathrm{cm}^{3}$. Finally, Umale et al. [15] confirmed the $4 \mathrm{~J}$ threshold for kidney injury.

In all these studies the tissue samples or organs were placed on a solid surface and impacted directly without taking overlaying soft tissue into account. For this reason, these threshold values cannot easily be transferred to humans where the organs are surrounded by soft tissue.

The goal of this study was to relate a blunt impact (e.g. of a LLIW projectile) and its mechanical parameters of impact energy and strain energy density to the injury severity and to investigate the influence of the overlaying soft tissue thickness. For this reason a gelatin model with an embedded organ mimicking a human body was chosen disregarding the protective influence of any bone structures. A FEM model using material parameters derived from the literature was developed to correlate experimental data to strain energy density values to predict organ responses and possible injuries to blunt impacts. 


\section{Materials and Method}

All experiments were performed using pig kidneys, since several publications revealed that the stress-strain curves of porcine kidney $[8,9,17]$ coincide with those of human kidney $[5,9,17]$. Besides, it was not possible to obtain human kidneys of the necessary numbers.

The pigs were slaughtered in a common slaughterhouse with the adipose capsule, ureter, and the renal vessels left intact. Shortly after, they were stored at $4{ }^{\circ} \mathrm{C}$. Within the next 12 hours the organs were taken out of the fat capsule and perfused with a saline solution. This was done through the artery until the liquid exited through the vein, with the saline solution bag hanging $1.4 \mathrm{~m}$ above the kidney to simulate a physiological pressure. The organs were weighed before (mean mass $193 \pm 30 \mathrm{~g})$ and after the filling resulting in a mean filling mass of $26 \pm 10 \mathrm{~g}(\mathrm{n}=101)$. Kidneys with obvious cysts or any kind of damage were excluded. The age of the slaughtered pigs was unknown.

As a soft tissue simulant around the kidneys ballistic gelatin Type 3 from GELITA at $10 \mathrm{wt} \%$ and $4{ }^{\circ} \mathrm{C}$ was used. The stress-strain curves of gelatin $[18,19]$ are within the dispersion of porcine muscle [20], rabbit muscle [20], and human muscle, skin, and fat [21] .

To fit the soft tissue dimensions covering the kidney in humans the best, we used the values from CT-scans of 15 male and 15 female dead bodies of normal weight from the institute's medico-legal data base. For each scan, the distance between body surface and kidney surface was recorded. The mean value for females was $32 \mathrm{~mm}$ [male $40 \mathrm{~mm}$ ], the maximum $43 \mathrm{~mm}$ [55 mm], and the minimum $16 \mathrm{~mm}[17 \mathrm{~mm}]$. Based on these results a gelatin layer thickness of 2 and $4 \mathrm{~cm}$ (error $\pm 5 \mathrm{~mm}$ ) was chosen for the experiments.

To prepare the body model, the liquid gelatin was filled into a mold of $25 \mathrm{x} 40 \mathrm{~cm}$ to a height of $9 \mathrm{~cm}$. After hardening the gelatin in the refrigerator $\left(12 \mathrm{~h}\right.$ at $\left.4{ }^{\circ} \mathrm{C}\right)$, a filled kidney organ was placed on top of it and an additional layer of gelatin was poured over such that the organ was covered with a gelatin layer of either $2 \mathrm{~cm}$ or $4 \mathrm{~cm}$ thickness. The liquid gelatin had a temperature of $34^{\circ}-39^{\circ} \mathrm{C}$ in order not to exceed the body temperature of a living pig causing any damage to the organs. The blocks were refrigerated again at $4{ }^{\circ} \mathrm{C}$ for 24 to 48 hours. The two gelatin layers bound together well and stayed bound ever after the impact.

The gelatin blocks were then placed below a drop tower with an impactor having a round tip with a diameter of $5 \mathrm{~cm}$ and a mass of $2.032 \mathrm{~kg}$ (see Fig. 1). An acceleration sensor (Kistler KShear Accelerometer 8704B500) was attached to the impactor. It was connected to an amplifier (Kistler 5015A) and the data was recorded during the drop tests by a TraNET FE (Elsys) transient-recorder at a sampling rate of $1 \mathrm{MHz}$.

The impactor was dropped from a height, measured by a laser rangefinder, between 0.6 and $1.8 \mathrm{~m}$ for the $2 \mathrm{~cm}$ gelatin layer and from 1.4 to $2.2 \mathrm{~m}$ for the $4 \mathrm{~cm}$ layer. The height was changed in steps of $0.2 \pm 0.005 \mathrm{~m}$. The difference between each step $(0.2 \mathrm{~m})$ corresponds to an energy increment of $4 \mathrm{~J}$. Per energy level, at least 8 organs were tested. In total, 61 organs were impacted with a $2 \mathrm{~cm}$ top layer and 40 with a $4 \mathrm{~cm}$ top layer. The gelatin temperature was regularly measured during the drop tests; it never exceeded $6.5^{\circ} \mathrm{C}$. This guaranteed that the mechanical properties of the gelatin stayed constant during the length of the experiment [19] and are comparable to soft tissue. We are however well aware that choosing a sample temperature of around $4{ }^{\circ} \mathrm{C}$ instead of body temperature surely influences the stress-strain 
behavior of the kidney. This means that the threshold values determined in this study have to be considered as the upper limit for kidney injury.

Additionally, for each height, 3 impacts were performed on gelatin blocks of the same dimensions but without an embedded organ. The acceleration signals of the impactor were recorded for comparing to results derived from a FEM model developed for the present study. This could be done since the stress-strain curve of ballistic gelatin at $4{ }^{\circ} \mathrm{C}[18,19]$ almost equals that of porcine kidneys [7-9,17]. The FEM model was done using Abaqus/CAE 2016, combining an axisymmetric geometry with a Mooney-Rivelin material model with parameters $\mathrm{c}_{1}=4558 \mathrm{~Pa}$ and $\mathrm{c}_{2}=7442 \mathrm{~Pa}$ [18]. These values were determined by matching the parameters of a FEM model to the experimental data of a compression experiment on gelatin performed under a strain rate of $0.208 / \mathrm{s}$, which fits the strain rates used in this study $(0-40 / \mathrm{s})$. The FEM model allows to determine the maximum strain energy density (SED) inside any voxel of the gelatin model. The maximum SED was determined inside the voxel (volume $\mathrm{V}=$ $0.19 \mathrm{~cm}^{3}$ ) located on the symmetry axis at a depth of $2 \mathrm{~cm}$ and $4 \mathrm{~cm}$, respectively and at the time corresponding to the maximum deformation.

To visualize the deformation of the kidney under impact a few impacts were recorded with a high speed (HS) camera (Photron FASTCAM SA-X2) set to 2000 fps illuminated by a LEDBooster light source. For this reason the gelatin blocks with the embedded kidney were placed in a glass container filled with cold water $\left(4^{\circ} \mathrm{C}\right)$ up to the top surface of the gelatin. This allowed us to take pictures through a perfectly smooth surface taking advantage of the close refractive index between water and gelatin. Care was taken that the water did not cover the top surface or influenced the measurement in any other way.

After the impact the organs were removed from the gelatin and examined visually for injuries, which were photographically documented. The organ was then cut and the depth of the lacerations and affected structures were documented. The injuries were classified according to the abbreviated injury scale (AIS) [22] see Table 1. As the study was done in vitro, only lacerations but not contusions could be considered. The organs were first categorized into damaged and undamaged. Additionally, the damage was categorized in injury severity $<$ AIS 3 or $\geq$ AIS 3 because from a clinical point of view, injuries above AIS 3, often require surgery

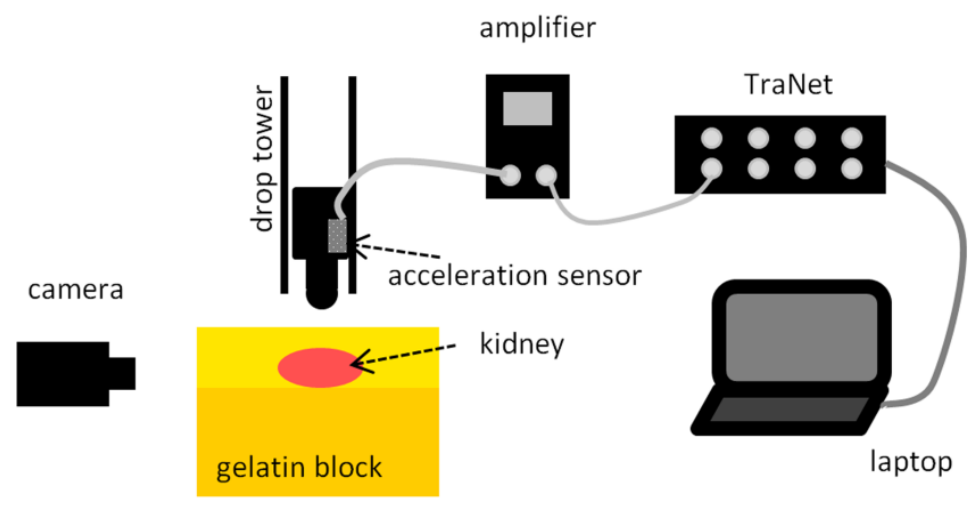

Fig. 1 Schematic setup, dark orange shows the part of the gelatin block that was first hardened, the light orange is the gelatin that was filled around the organ 
[23-25]. The probability of a damage and a damage $\geq$ AIS 3 was calculated for each height (number of damaged organs divided by total number of organs).

Table 1 Abbreviated injury scale (AIS) of the kidney [22]

\begin{tabular}{|c|c|}
\hline AIS & Injury description \\
\hline $\begin{array}{l}2 \\
3\end{array}$ & $\begin{array}{l}\text { Contusion; } \\
\text { subcapsular, nonexpanding; confined to renal retroperitoneum; minor; superficial } \\
\text { subcapsular, >50\% surface area or expanding; major; large }\end{array}$ \\
\hline 2 & $\begin{array}{l}\text { Laceration; } \\
\leq 1 \mathrm{~cm} \text { parenchymal depth of renal cortex, no urinary extravasation; minor; superficial }\end{array}$ \\
\hline 3 & $\begin{array}{l}>1 \mathrm{~cm} \text { parenchymal depth of renal cortex, no collecting system rupture or urinary } \\
\text { extravasation; moderate }\end{array}$ \\
\hline 4 & $\begin{array}{l}\text { extending through renal cortex, medulla and collecting system; main renal vessel injury } \\
\text { with contained hemorrhage; major }\end{array}$ \\
\hline 5 & hilum avulsion; total destruction of organ and its vascular system \\
\hline
\end{tabular}

\section{Results}

The kidney injuries caused by the impactor ranged from small tears to large destructions reaching the renal sinus fat tissue and renal collecting system. However, even for the strongest impacts no tears were found inside the medulla and the collecting system, which means that no damage corresponding to the category AIS 4 was caused by the impact energies applied in this study.

Typical kidney damage pictures of AIS 3 injuries can be seen in Fig. 2. On the impact side (A) the biggest damage is located underneath the impact area. On the opposite side (B) the damage is located foremost to both sides of the kidney. These tears were caused by the strong bending of the organ, which can be seen in the image taken $21.5 \mathrm{~ms}$ after the impactor had touched the model surface (see Fig. 3). The cut through the kidney clearly reveals that the tears did not reach the renal sinus fat tissue and renal collecting system (Fig. 2C). The high speed images taken during the interaction of the impactor (Fig. 3) with the embedded kidney show the gradual deformation of the kidney. Although the impactor strongly compressed the gelatinkidney sample, the gelatin surface remained undamaged during the impact (see Fig. 3 after

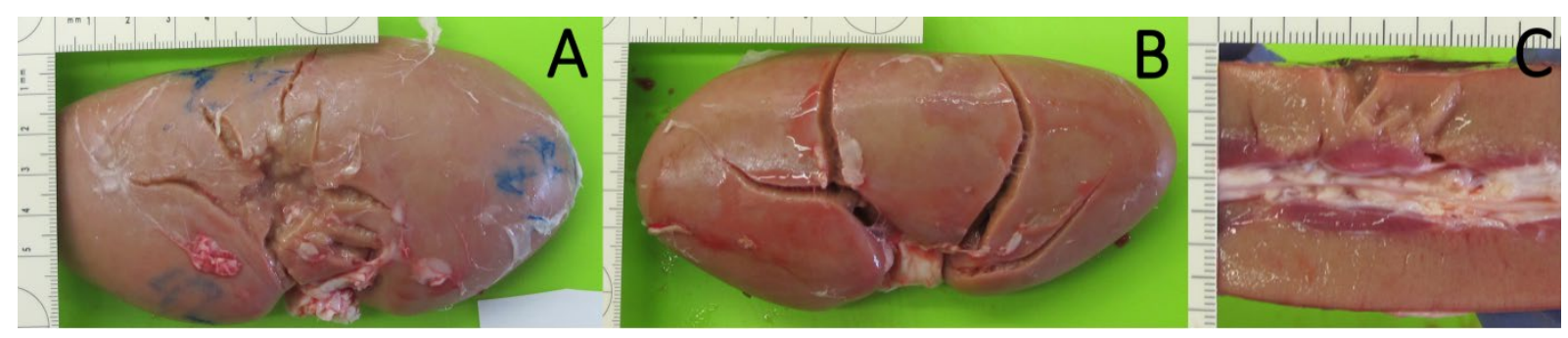

Fig. 2 Typical damage of the kidney corresponding to AIS 3: (A) impact side of the kidney, (B) opposite side of the impact, (C) cut through the kidney showing the damaged tissue with intact medulla and collecting system. Impact energy $=32 \mathrm{~J}$, gelation layer thickness $=2 \mathrm{~cm}$ 
impact). The turbulences seen near the surface of the model in front of the impactor (Fig. 3 at $21.5 \mathrm{~ms}$ ) visualize the water flow caused by the strong deformation of the model inside the glass container.

The $50 \%$ probability for kidney damage was found to be at an impact energy of $22 \mathrm{~J}$ for the kidney covered by a $2 \mathrm{~cm}$ thick gelatin layer and of $32 \mathrm{~J}$ for a layer thickness of $4 \mathrm{~cm}$ (see Fig. 4). The $50 \%$ probability value for generating a kidney injury of a scale $\geq$ AIS 3 was found at $27 \mathrm{~J}$ and $36 \mathrm{~J}$ for the $2 \mathrm{~cm}$ and $4 \mathrm{~cm}$ thick gelatin layer, respectively (Fig. 5).

The comparison of Fig. 4 and Fig. 5 reveals that an increase of the covered gelatin layer thickness from $2 \mathrm{~cm}$ to $4 \mathrm{~cm}$ increases the $50 \%$ probability threshold in both cases by about $10 \mathrm{~J}$.

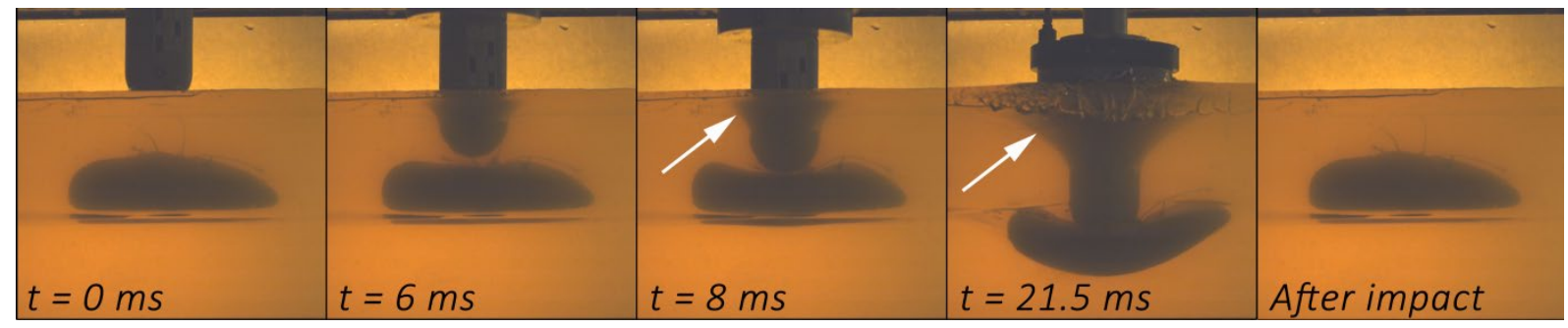

Fig. 3 High speed images of the impact. Example with an impact energy of $36 \mathrm{~J}$ and a gelatin layer of $4 \mathrm{~cm}$. First, local deformation on the organ $(\mathrm{t}=8 \mathrm{~ms})$, then the whole organ is pressed into the gelatin. At $21.5 \mathrm{~ms}$ the deepest position is reached. At $\mathrm{t}=21.5 \mathrm{~ms}$ some water turbulences can be seen on the surface of the sample. A comparison between the first and the last image reveals that the gelatin block was not damaged by the impact. The white arrows indicate the surface deformation of the gelatin

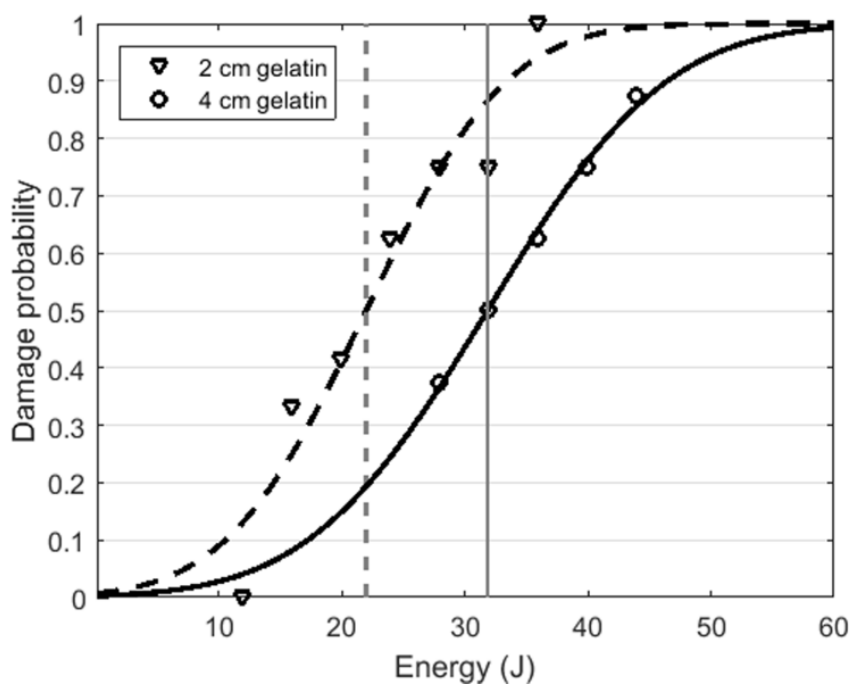

Fig. 4 Damage probability values for a classification in damaged and undamaged. Black lines: fit of the cumulative distribution. Vertical gray lines: 50\% threshold values 


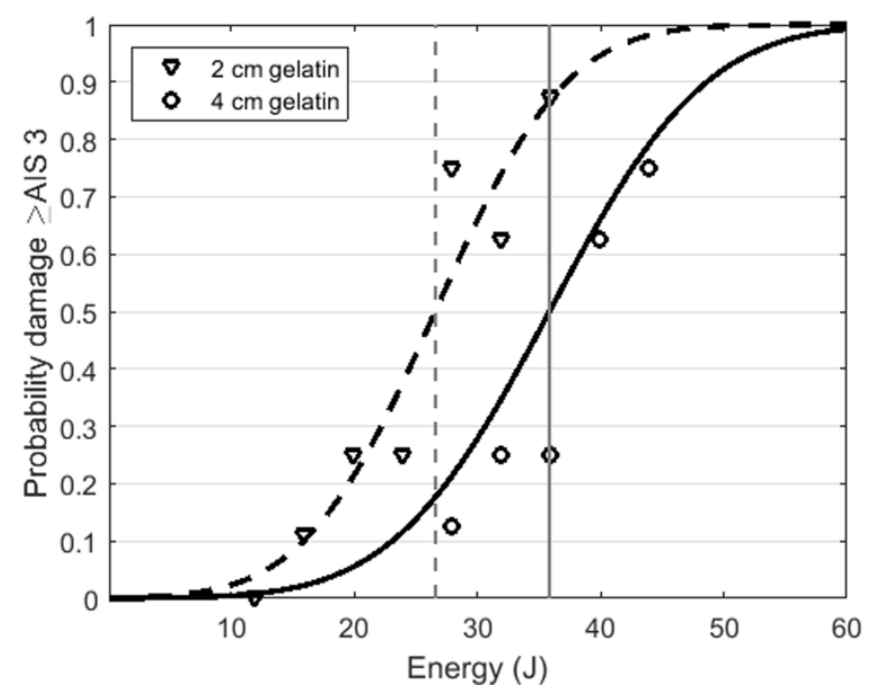

Fig. 5 Probability for a damage $\geq$ AIS 3. Black lines: fit of the cumulative distribution. Vertical gray lines: $50 \%$ threshold values

The almost perfect agreement of the acceleration data measured during experiments performed with an organ embedded into gelatin and with just a gelatin block without an organ revealed that the mechanical properties of ballistic gelatin indeed mimic kidney tissue. The only difference found was that the experimental results obtained with an embedded organ showed a stronger scattering due to variations of shape and size of the embedded organs. This fact encouraged us to develop a FEM model based on gelatin data.

Fig. 6 shows that the experimental results of the acceleration agree very well for all the considered drop heights with the values derived from the FEM model using material parameters

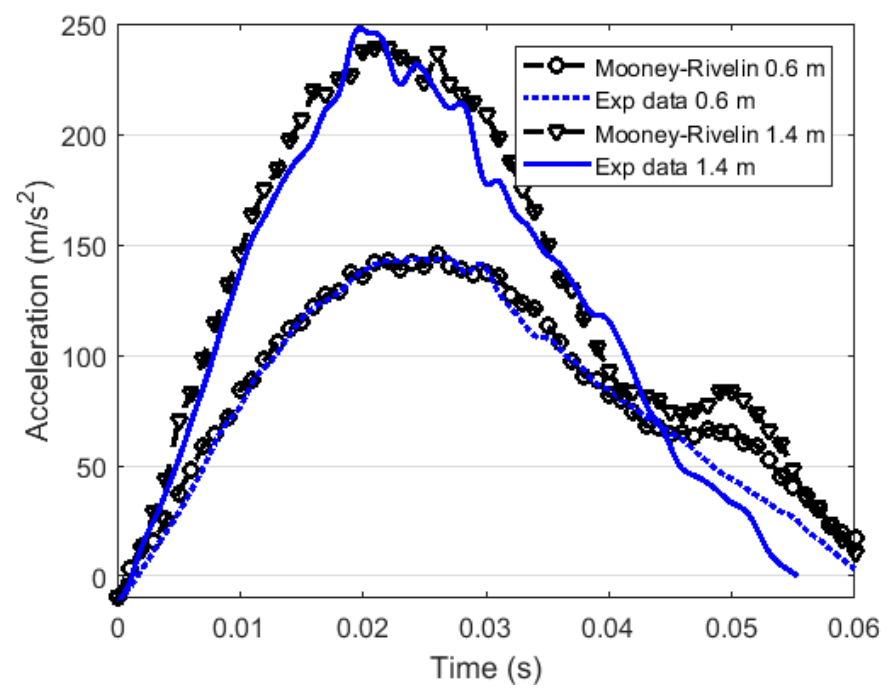

Fig. 6 Acceleration data of the impactor for a height of $0.6 \mathrm{~m}$ corresponding to an impact energy of $12 \mathrm{~J}$ and a height of $1.4 \mathrm{~m}$ corresponding to an energy of $28 \mathrm{~J}$ compared to the MooneyRivelin model using the mechanical parameters proposed by Liu et al. [18] 


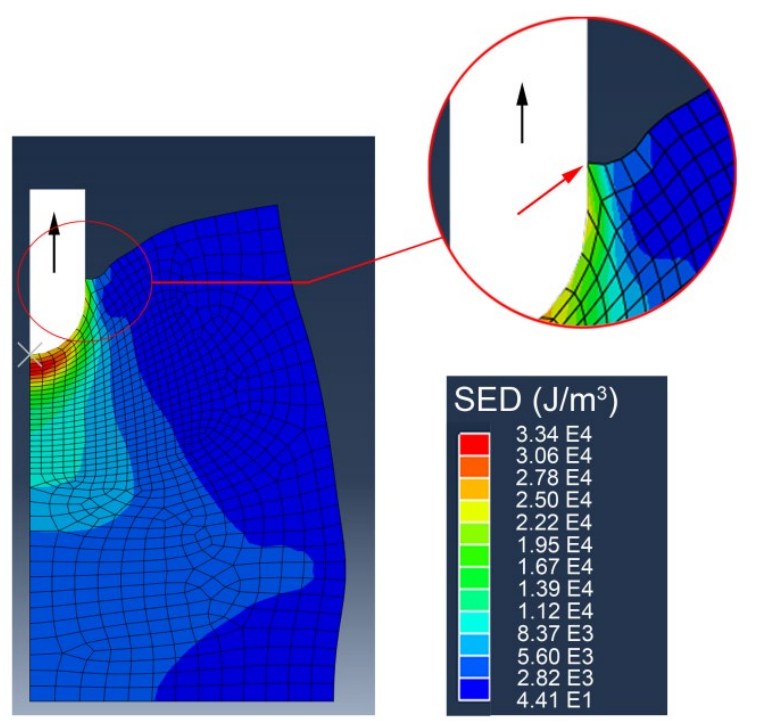

published by Liu et al. [18]. Only after about $\mathrm{t}=40 \mathrm{~ms}$ deviate the simulated from the experimental values. This deviation can be explained by contact friction, which makes the gelatin stick to the impactor surface during the rebound phase as seen in Fig. 7, which shows a simulation of the impactor when retreating from the gelatin. This deviation between model and experiment appearing only in the pullback phase of the impactor did not influence the derived maximum SED values calculated for the 50\% energy threshold values derived from Fig. 4 and Fig. 5.

For the damage threshold a strain energy density value of $88.9 \mathrm{~mJ} / \mathrm{cm}^{3}(2 \mathrm{~cm}$ gelatin layer) and of $86.7 \mathrm{~mJ} / \mathrm{cm}^{3}$ (4 cm layer) was found. Using impact energies causing a $50 \%$ probability of an injury severity of $\geq$ AIS 3 strain energy densities of $104.2 \mathrm{~mJ} / \mathrm{cm}^{3}$ at $2 \mathrm{~cm}$ and of $98.7 \mathrm{~mJ} / \mathrm{cm}^{3}$ at $4 \mathrm{~cm}$ were found.

\section{Discussion}

Fig. 7 Axisymmetric model of the impactor retreating from the gelatin at $0.05 \mathrm{~s}$ (black arrow indicates direction). Impact energy $\mathrm{E}=36 \mathrm{~J}$. The gelatin block shows the chosen mesh with the SED distribution. Enlarged: Section showing the interface between the impactor and the gelatin with the gelatin sticking to the impactor (red arrow)

The goal of this study was to determine the threshold energy for kidney injury when the organ is embedded into soft media. The good agreement between the experimental acceleration data measured on the impactor when hitting the sample consisting of ballistic gelatin with and without an embedded organ and the simulated ones based on the Mooney-Rivelin material model using experimentally determined parameters (see Fig. 6) confirmed that ballistic gelatin at $4{ }^{\circ} \mathrm{C}$ is an ideal substance to simulate mechanical properties of soft tissue. In consequence, the strain energy density calculated by the FEM model under an impact energy corresponding to the $50 \%$ damage threshold (see Fig. 4 and 5) seems to provide a realistic picture of kidney injury. This is supported by the fact that the SED at the 50\% damage threshold was found to be independent of the thickness of the soft tissue layer covering the organ. The fact that the SED 
values related to an organ injury determined in this study are much higher than values found in the literature [11-16] has three reasons: (i) the literature data were obtained by slowly squeezing tissue samples or the whole organ between two hard plates which hindered the organ to bend as expected in a realistic situation of blunt impact; (ii) the literature data represent mean values over a large sample volume or even the whole organ whereas our data display the SED inside one single voxel; (iii) in this study the organs were surrounded by gelatin, which has a protecting effect on the organ.

The studies found in the literature reported a threshold value for injuries with an AIS 3 of $4 \mathrm{~J}$ [11,13-15] and for a first sign of kidney injury at 1.4 or $2.7 \mathrm{~J}$ [11,12], which are at least 5 times lower than the values determined in this study (see Fig. 4 and 5). This large discrepancy is again caused by the difference in the experimental setup. Whereas in the experiments performed by Umala et al. [15] and Schmitt et al. [13] the organ was hit directly by the impactor, the organs in this study were covered and surrounded by soft gelatin. A $2 \mathrm{~cm}$ increase of the layer thickness leads already to a $10 \mathrm{~J}$ increase of the threshold. In addition, the threshold energy is increased by the presence of a soft background. In a forensic case the thickness of the abdominal layers must therefore be taken into account if the severity of an injury is used to retrieve the applied impact energy. This means that for example an AIS 3 kidney injury on an obese person must have been caused by a much stronger impact than on a slim person.

Our results can be put in context with the use of LLIWs. For the worst case scenario investigated in this study with a hard projectile, no attenuation of clothing, and a hit on the soft tissue above the organ on a slim person (abdominal layer of $2 \mathrm{~cm}$ ) the impact energy must be kept below approx. $10 \mathrm{~J}$ (corresponding to a $10 \%$ threshold value) to be sure to avoid any damage to the kidney. If there is a willingness to take injuries of an AIS 2 into account the impact energy must stay below approx. $15 \mathrm{~J}$ (10\% threshold value). These energies can however be higher if the projectile has an attenuating structure.

As an example, some of the Swiss police force is using the SIR projectiles (manufacturer B\&T). A minimum safety distance of $5 \mathrm{~m}$ was defined corresponding to an impact energy of $109 \mathrm{~J}^{1}$. For a worst case scenario of a hypothetical incompressible projectile this energy takes injuries far exceeding AIS 3 into account. In reality the clothing, the partial protection of the ribs, the attenuating soft surface of the SIR projectile and a usually larger distance between LLIW and the person shot at reduces the risk of a severe kidney injury. For example, the initial energy of $109 \mathrm{~J}$ drops to $36 \mathrm{~J}$ at a distance of $95 \mathrm{~m}$ and to $27 \mathrm{~J}$ at a distance of $122 \mathrm{~m}^{1}$. The influence of the attenuating structure for different projectile compositions should be subject of further investigation.

Although, only kidneys were investigated in the present study the determined energy threshold values could also be used at least as a first assumption for other organs having similar mechanical properties such as the liver. The application of these results to other organs and in a next step the additional protective influence of bones (ribs) must also be further investigated to be able to give the authorities scientifically validated damage threshold values.

\footnotetext{
${ }^{1}$ Data taken from internal measurements
} 


\section{Conclusion}

The investigations showed a clear correlation between the impacting energy and the resulting organ damage. It was further shown that the soft tissue surrounding the organ strongly affects the threshold of the impact energy. The results of this study show that in forensic cases the abdominal layer thickness must be considered when an impact energy is to be determined from the injury.

\section{Acknowledgements}

The authors declare that they have no conflict of interest. This research was partially supported by BAAINBw and armasuisse $\mathrm{W}+\mathrm{T}$, two governmental procurement agencies. We would like to thank Prof. Michael Stoffel, Vetsuisse Faculty Bern, for his precious help choosing the appropriate simulants.

\section{References}

1. Augenstein J, Perdeck E, Bowen J, Stratton J, Singer M, Horton T, Rao A, Digges K, Malliaris A, Steps J (1999) Injuries in Near-Side Collisions. Annual Proceedings / Association for the Advancement of Automotive Medicine 43:139-158

2. Rouhana SW (2002) Biomechanics of Abdominal Trauma. In: Nahum AM, Melvin JW (eds) Accidental Injury: Biomechanics and Prevention. Springer New York, New York, NY, pp 405-453. doi:10.1007/978-0-387-21787-1_17

3. Lau IV, Horsch JD, Viano DC, Andrzejak DV (1987) Biomechanics of liver injury by steering wheel loading. J Trauma 27 (3):225-235. doi:10.1097/00005373-198703000-00001

4. Carmona RH, Lim RC, Jr., Clark GC (1982) Morbidity and mortality in hepatic trauma. A 5 year study. American journal of surgery 144 (1):88-94. doi:10.1016/0002-9610(82)90607-9

5. Karimi A, Shojaei A (2017) Measurement of the Mechanical Properties of the Human Kidney. IRBM 38 (5):292-297. doi:10.1016/j.irbm.2017.08.001

6. Nasseri S, Bilston LE, Phan-Thien N (2002) Viscoelastic properties of pig kidney in shear, experimental results and modelling. Rheologica Acta 41 (1):180-192. doi:10.1007/s003970200017

7. Farshad M, Barbezat M, Flüeler P, Schmidlin F, Graber P, Niederer P (1999) Material characterization of the pig kidney in relation with the biomechanical analysis of renal trauma. Journal of Biomechanics 32 (4):417-425. doi:10.1016/S0021-9290(98)00180-8

8. Umale S, Deck C, Bourdet N, Dhumane P, Soler L, Marescaux J, Willinger R (2013) Experimental mechanical characterization of abdominal organs: liver, kidney \& spleen. Journal of the Mechanical Behavior of Biomedical Materials 17:22-33. doi:10.1016/j.jmbbm.2012.07.010 
9. Snedeker JG, Niederer P, Schmidlin FR, Farshad M, Demetropoulos CK, Lee JB, Yang KH (2005) Strain-rate dependent material properties of the porcine and human kidney capsule. Journal of Biomechanics 38 (5):1011-1021. doi:10.1016/j.jbiomech.2004.05.036

10. Nicolle S, Palierne JF (2010) Dehydration effect on the mechanical behaviour of biological soft tissues: Observations on kidney tissues. Journal of the Mechanical Behavior of Biomedical Materials 3 (8):630-635. doi:https://doi.org/10.1016/j.jmbbm.2010.07.010

11. Bschleipfer T, Kallieris D, Hauck EW, Weidner W, Pust RA (2002) Blunt Renal Trauma: Biomechanics and Origination of Renal Lesions. European Urology 42 (6):614-621. doi:https://doi.org/10.1016/S0302-2838(02)00437-2

12. Snedeker JG, Barbezat M, Niederer P, Schmidlin FR, Farshad M (2005) Strain energy density as a rupture criterion for the kidney: impact tests on porcine organs, finite element simulation, and a baseline comparison between human and porcine tissues. J Biomech 38 (5):993-1001. doi:10.1016/j.jbiomech.2004.05.030

13. Schmitt KU, Snedeker JG (2006) Kidney injury: an experimental investigation of blunt renal trauma. J Trauma 60 (4):880-884. doi:10.1097/01.ta.0000215573.19136.04

14. Schmitt KU, Snedeker JG (2006) Analysis of the biomechanical response of kidneys under blunt impact. Traffic Inj Prev 7 (2):171-181. doi:10.1080/15389580500482021

15. Umale S, Deck C, Bourdet N, Diana M, Soler L, Willinger R (2015) Experimental and finite element analysis for prediction of kidney injury under blunt impact. Journal of Biomechanics 52:2-10. doi:https://doi.org/10.1016/j.jbiomech.2015.06.011

16. Melvin JW, Stalnaker RL, Roberts VL, Trollope ML Impact Injury Mechanisms in Abdominal Organs. In: 17th Stapp Car Crash Conference, 1973/02/01/ 1973. SAE Technical Paper, Warrendale, PA. doi:10.4271/730968

17. Helfenstein-Didier C, Tanter M, Gennisson JL, Beillas P (2015) Observation of the internal response of the kidney during compressive loading using ultrafast ultrasonography. Journal of Biomechanics 48 (10):1852-1859. doi:https://doi.org/10.1016/j.jbiomech.2015.04.033

18. Liu L, Jia Z, Ma X, Fan Y, Li W, Liu H (2014) A spherical cavity expansion model of large elastic deformation and its application to ballistic gelatin penetration problems. International Journal of Impact Engineering 71:106-116. doi:10.1016/j.ijimpeng.2014.04.007

19. Cronin DS, Falzon C (2011) Characterization of $10 \%$ Ballistic Gelatin to Evaluate Temperature, Aging and Strain Rate Effects. Exp Mech 51 (7):1197-1206. doi:10.1007/s11340-010-9438-Z

20. Van Loocke M, Lyons CG, Simms CK (2006) A validated model of passive muscle in compression. Journal of Biomechanics 39 (16):2999-3009. doi:10.1016/j.jbiomech.2005.10.016

21. Zheng Y, Mak AF, Lue B (1999) Objective assessment of limb tissue elasticity: development of a manual indentation procedure. Journal of rehabilitation research and development 36 (2):71-85 
22. AAAM (2008) The Abbreviated Injury Scale 2005; Update 2008. Association for the Advancement of Automotive Medicine, Des Plaines, IL

23. Heuer M, Hussmann B, Schenck M, Nast-Kolb D, Ruchholtz S, Lefering R, Paul A, Taeger G, Lendemans S, DGU Td (2012) Nierenverletzung und Polytrauma: Outcome, Verlauf und Behandlungsalgorithmus. Der Unfallchirurg 115 (8):700-707. doi:10.1007/s00113-010-1909-2

24. Santucci RA, McAninch JM (2001) Grade IV renal injuries: evaluation, treatment, and outcome. World journal of surgery 25 (12):1565-1572. doi:10.1007/s00268-001-0151-Z

25. Santucci RA, McAninch JW, Safir M, Mario LA, Service S, Segal MR (2001) Validation of the American Association for the Surgery of Trauma organ injury severity scale for the kidney. J Trauma 50 (2):195-200. doi:10.1097/00005373-200102000-00002 